\title{
College students' perceptions of a caring climate in group physical activity classes
}

\author{
Aubrey Newland ${ }^{1}$, Maria Newton ${ }^{2}$, Andrea Stark ${ }^{3}$, Leslie Podlog ${ }^{2}$, Morgan Hall ${ }^{2}$ \\ ${ }^{1}$ California State University, Chico, USA; ${ }^{2}$ University of Utah, USA; ${ }^{3}$ University of Minnesota, USA
}

\section{Summary}

Study aim: Research suggests that physical activity rates decline sharply after high school. The pattern of activity or inactivity during college tends to persist into adulthood. A critical need exists for examination of strategies to engage college-age students in physical activity habits. One way to do this is through physical activity courses offered in colleges. This study examines the relationship between perceptions of a caring psychological climate and group connectedness, enjoyment, and attitudes toward classmates and the instructor in group physical activity courses.

Material and methods: Participants were 174 students $(107$ males and 67 females; Mage $=21.71)$ enrolled in exercise, martial arts, and sports courses at a large university in the Mountain West.

Results: Perceptions of a caring climate were significantly related to enhanced feelings of group connectedness, heightened enjoyment, and more positive attitudes toward classmates and instructor.

Discussion: These findings suggest that a strategy to foster engagement in physical activity courses on campus is to train instructors to value, support, and welcome students.

\section{Keywords: College students - Physical activity - Group exercise - Caring - Motivation}

\section{Introduction}

Across the developmental spectrum, there is increasing concern about a lack of physical activity. Research suggests a steady decline in physical activity throughout the lifespan [48] and a specific decline during adolescence [14]. However, there is limited support for the "carryover" hypothesis, which suggests that behaviors in adulthood are likely "carried over" from younger ages [24, 25]. The transition from teenage years to young adulthood may also be a time ripe for change because of the increased autonomy and feelings of empowerment that accompany this developmental shift. Thus, focusing on developing physical activity patterns in college-aged young adults may be valuable.

Rates of vigorous physical activity fall dramatically after high school. In a nationally representative sample of over 10,000 college students, Nelson and colleagues reported a sharp decline in the number of students meeting the criteria for vigorous physical activity as they transition from high school to college [33]. In high school 68\% of females and $74 \%$ of males met the criteria from the Center for Disease Control and the American College of
Sports Medicine (20 minutes or more of vigorous physical activity on at least 3 days of the week). In college the percentages drop to $44 \%$ of females and $52 \%$ of males. Rates of inactivity are equally divergent. In high school $11 \%$ of males and $15 \%$ of females are inactive. The percentages almost double in college (19\% of males and $26 \%$ of females). Buckworth and Nigg's [10] finding that college students spend almost 30 hours a week engaged in sedentary activity support these data. While rates of physical activity steadily decline in college [33] it is true that habits formed during college tend to be fairly well sustained. Calfas and colleagues [11] reported that $84.7 \%$ of college seniors who exercised regularly were active a decade later. Unfortunately, the opposite appears to be true as well; $80 \%$ of inactive college seniors continue their sedentary behavioral patterns after college [10, 33, 43, 50]. Given that engaging in physical activity leads to a host of well-established physiological and psychological benefits [5, 18, 46, 48, 49] and that lack of physical activity is a modifiable risk factor of chronic disease understanding how to enhance the college students' experience in physical activity is critical. Deepening our knowledge in this area may lead to innovative strategies to foster physical activity in college students. To explore this issue we 
examined the relationship between perceptions of a caring social psychological climate and indices of optimal engagement in college students enrolled in group physical activity classes.

According to social cognitive theory (SCT), behaviors are regulated by the interaction of environment, personal, and behavioral factors [4]. As a result of these interacting factors, decisions are made which affect self-regulation and physical and emotional well-being [4]. For example, decisions to adopt healthy behaviors are guided by the desire for social interaction and support [50] and enjoyment [37]. Issues of accessibility and availability of facilities also play a role in the adoption of a regular physical activity [27]. For college students, one way to address these needs for social interaction and availability of facilities is through group physical activity courses on campus.

Group physical activity courses are a popular venue for engaging in physical activity on college campuses. The number of group physical activity courses offered and students served per semester varies by campus, but in general is quite large. For instance, two large universities in the Midwest and South regions of the United States offered over 100 group fitness courses the fall semester of 2014. During that same time frame, a university in the Mountain West region offered over 200 courses serving over 4000 students. Such breadth of opportunities and depth in terms of participation suggest that the programs are prevalent and popular to the student body, and that they are worthy of investigation. The types of opportunities are varied and diverse - with typically mixed-gender courses. Traditional sport courses such as basketball, volleyball, and tennis are often available. Exercise courses are also an option and include, for example, circuit training, Zumba ${ }^{\circledR}, \mathrm{CrossFit}^{\mathbb{}}$, water aerobics, and marathon training. Martial arts courses are often made available and include courses such as judo, aikido, and tae kwon do. Providing a large variety of courses allows students to select an activity corresponding to their interests. Moreover, the variety in experiences extends to the nature of the social psychological climate present in these courses.

Exercisers in a group physical activity class [8,9], students in classroom [1] or physical education [23] settings, as well as athletes on sports teams $[41,52]$ all perceive a social psychological climate. The social psychological climate refers to participants' perceptions of what is emphasized and valued in a particular context $[1,2,34$, 41]. One aspect of the social psychological climate, a caring climate, is defined as "the extent to which individuals perceive a particular setting to be interpersonally inviting, safe, supportive and able to provide the experience of being valued and respected" [34]. Based on the work of Noddings [35] in relation to care theory, caring captures a set of relational practices between the one-caring (the group exercise leader, in this case) and the cared-for (students in the class) that result in an optimization of experience [36]. A caring relation between the one-caring and the cared-for is marked by engrossment and motivational displacement $[35,36]$. Engrossment is evident when the one-caring (instructor) values and is fully accepting and welcoming of the cared-for (student). Motivational displacement occurs when the one-caring is nonjudgmental, respectful of the goals of the cared-for and able to connect with the caredfor in a way that encourages their effectance motivation [36]. While caring often emanates from the behaviors and actions of the one-caring to the cared-for, it is also propitious and influential when the cared-for behave with engrossment and motivational displacement with each other and with the one-caring [35].

Researchers have examined the relevance of caring climates in a variety of group settings involving physical activity. Notably, perceptions of a caring climate negatively predicted bullying in a physical education setting [23]. In separate investigations, Fry and colleagues reported positive associations between caring and enjoyment and positive attitudes in adolescent community soccer leagues [21], as well as hope and happiness in a physical activity setting [22]. From these findings it is reasonable to infer that the extent to which individuals feel valued and respected in group settings has implications for interpersonal relationships and the affective experience of group members. The importance of caring in group exercise settings is the focus of this study.

Caring might be particularly relevant for individuals in group exercise settings where individuals must publically display their bodies and levels of fitness while engaging in a variety of movements and exercises in front of and with others. For college students, this may be particularly challenging. Issues surrounding body image and health behaviors are a pressing concern for college students [29]. When college students feel cared for in a way that invites engagement and interpersonal support, they may be more willing and comfortable engaging in physical activity in these settings. Brown and Fry [9] discovered that among participants in college exercise classes perceptions of a caring climate were positively associated with physical self-concept. A growing body of research supports the importance of a caring climate in exercise settings. For example, Brown and Fry [8] examined females' perceptions of their aerobics classes in a college setting and found perceptions of a caring climate were related to higher enjoyment, increased effort, and greater commitment to exercise. Leslie and colleagues [30] found that a significantly greater percentage of Australian college students who reported high levels of emotional social support (e.g., encouragement, empathy, and concern) were more physically active than those reporting low levels of emotional support. Furthermore, research has examined the impact of training exercise leaders to teach in a socially enriched 
style $[19,30]$, with a focus on emphasizing personal interaction and displaying social support, positive encouragement, and reinforcement. Teaching in a socially enriching manner resulted in greater exercise enjoyment [19, 30]. The characteristics of emotional social support and social enrichment share much in common with caring. The aforementioned literature provides a rationale for examining caring in physical activity settings and is the basis for our hypothesis that caring will be positively related to engagement among college students enrolled in group exercise courses.

For this study, engagement referred to key indicators of positive participation. We chose enjoyment, connectedness, and attitudes toward class, classmates, and instructors as the indicators of optimal engagement. Enjoyment has been recognized as an important determinant of physical activity in college students $[8,28]$. Connectedness is a key protective factor in late adolescence [38] and has been inversely linked to depression in college students [3], but remains unexplored in relation to physical activity in college students. Lastly, we explored students' attitudes toward their class, classmates, and instructors. Researchers have established that attitudes are predictive of physical activity in college students $[15,39]$. By assessing levels of enjoyment, feelings of connectedness, and attitudes toward class, classmates, and instructors, a sense of overall engagement in the class can be ascertained.

The primary purpose of this study was to examine the relationship between perceptions of a caring climate and indices of optimal engagement among college students enrolled in group physical activity courses. Specifically, relationships between perceptions of a caring climate and group connectedness, enjoyment, and attitudes toward classmates and the instructor were examined in exercise, martial arts, and sports courses. We hypothesized that caring would positively predict group connectedness, enjoyment, and attitudes toward classmates and the instructor. A secondary, exploratory purpose was to examine course type and sex differences in perceptions of caring. Sex differences in perceptions of caring have not been evident in prior research in physical education settings with younger participants [23], but it is unknown if this is the case with more mature participants. It is possible that as issues related to self-concept and body esteem [45] become more evident following puberty that caring might be more or less salient to a particular sex. The nature of instruction and class activities are inherently different in exercise, martial arts, and sport settings. The competitive nature of sport, the philosophical underpinnings of martial arts, and the focus on individual striving in exercise classes may account for differences in perceptions of caring in each setting. These questions are novel and no hypotheses were made for this purpose.

\section{Material and methods}

\section{Sample}

Participants were 174 college students ages 18-30 $(M=21.71$ years, $S D=3.10)$ at a moderately large university in the Mountain West region of the United States. Male $(n=107)$ and female $(n=67)$ participants classified themselves as Caucasian ( $\mathrm{n}=78.2 \%$ ), Hispanic $(n=5.2 \%)$, African American $(n=0.6 \%)$, Asian American $(n=5.7 \%)$, and other $(n=10.3 \%)$. Of the 26 instructors who were contacted to participate, three instructors elected not to participate in the study. Thus, 23 classes were surveyed. Classes were optional for all students (i.e., there was no requirement for a physical activity course) and costs were standard tuition charges across all classes. Credit for classes is given based on attendance and participation. Three types of courses were targeted, physical activity ( $n=12,45.3 \%$ of participants), sport ( $n=5,35.3 \%$ of participants), and martial arts ( $n=6,19.3 \%$ of participants). The physical activity courses included jogging for fitness, swimming, circuit training, triathlon, aquatone, weight training, and yoga. The sport courses consisted of basketball, volleyball, badminton, tennis, and racquetball. The martial arts courses were judo, aikido, tai chi, wing chun, and tae kwon do.

\section{Protocol}

University institutional review board (IRB) approval was obtained for research using human subjects. A variety of university fitness courses were selected. Data collection took place during the fifth week of an eight week semester to ensure that participants had sufficient time to form perceptions of the climate. With the permission of the fitness director and class instructors, surveys were distributed. A brief explanation of the study was given and questions were answered. Participation was voluntary and had no impact on the grade the student earned in the course. Completion of the questionnaires took approximately 10$15 \mathrm{~min}$. Data were collected as students arrived to class so that those wishing not to participate would not have their workout disturbed.

\section{Measures}

Perceptions of a Caring Climate. The Caring Climate Scale [34] (CCS) was slightly adapted and used to assess the extent to which the participants perceived their physical activity course, sport course, or martial arts course to be interpersonally inviting, safe, supportive, and able to provide the experience of being valued and respected. Minor adaptations were made to make it relevant to the study context. The terms "kids" and "leaders" were replaced by "classmates" or "instructor," respectively. The stem "In this class" was used for each item. Participants 
were asked to think about what their class and instructor are typically like and then circle the appropriate response. Example items include, "In this class the instructor is kind to class members" and "In this class members are treated with respect." The CCS contains 13 items measured on a 5-point Likert-type scale from 1 (strongly disagree) to 5 (strongly agree). Mean scale scores were computed. The CCS has been found to be valid and reliable with youth in physical activity contexts $[21,34]$. The internal reliability of the scores for the scale in this study was a highly acceptable .96 .

Enjoyment. The extent to which participants enjoy their physical activity or sport course was measured with the fiveitem satisfaction/enjoyment subscale of the intrinsic satisfaction scale created by Duda and Nicholls [13] to assess classroom and sport satisfaction. The items were slightly adapted to measure enjoyment in group physical activity and sport courses. Participants were requested to reflect on the class they were currently enrolled in. An example item is "I usually have fun doing (insert your physical activity/sport)." Items were responded to on a 5-point Likert-type scale ranging from 1 (strongly agree) to 5 (strongly disagree). This scale has been shown to be both valid and reliable in research using college-aged students [13]. The internal reliability in this study was an acceptable 0.92 .

Attitudes toward classmates and instructor. Five items were included to assess students' attitudes toward their classmates and instructor. Smith, Smoll, and Curtis [42] originally developed these items as independent measures in their work with coaching behaviors in Little League baseball). For this study, Fry and Newton's [20] adaptations of these items were used. Items assessed attitudes about their instructor (3 items; e.g., "How much would you like to have the same instructor again next year?") and their classmates (2 items; e.g., "How much do you like the other students in this class?"). Participants responded using a 5-point Likert-type scale ranging from 1 (not at all) to 5 (a lot). Prior research [22] has supported the internal consistency of these scales $(\alpha=0.82-0.91)$. In this study the instructor items were reliable $(\alpha=0.71)$ and the intercorrelation coefficient between the two classmates items was 0.84 , indicating that participants responded fairly consistently to the items.

Group connectedness. The extent to which class members felt connected to their classmates was measured with the Acceptance Subscale of the Need for Relatedness Scale [40] which was adapted by Standage, Duda, and Ntoumanis [43] for use in physical education settings. The directions on the scale were slightly modified for use in physical activity and sport settings, and requested that participants reflect on how they feel about their classmates. The scale includes five items with the stem, "With the people in my class I feel..." (a) "supported," (b) "understood," (c) "listened to," (d) "valued," and (e) "safe." Participants responded to the items using a 7-point Likert-type scale ranging from 1 (strongly disagree) to 7 (strongly agree). Standage and colleagues $[43,44]$ reported acceptable reliability for the scale ( $\alpha=0.88-0.91)$. The reliability of the scores of the scale in this study was a very acceptable 0.94 .

\section{Statistical analysis}

SPSS version 20 (SPSS IBM, New York, U.S.A.) was used to perform statistical analyses. Following data screening and cleaning, descriptive statistics (e.g., $M$, $S D$, ranges) were calculated for all measures. A two-way ANOVA was used to examine differences in perceptions of the caring climate by sex and course type. Simple correlations were computed followed by four simple linear regressions to examine the relationship of perceptions of a caring context and enjoyment, attitudes toward instructor and classmates, and group connectedness.

\section{Results}

\section{Differences by sex and course types}

A $2 \times 3($ Sex $\times$ Course type $)$ ANOVA was conducted to determine if the two sexes and three course types differed perceptions of the caring climate. The analysis revealed no significant differences by Sex, $F(1,144)=0.009, p=0.92$, Course type, $F(2,144)=0.758, p=0.47$, or Sex $\times$ Course type, $F(2,144)=1.675, p=0.19$.

\section{Descriptive statistics}

The descriptive statistics for the sample including scale reliabilities are provided in Table 1 . The group exercise participants perceived the climate in their class to be quite caring. Furthermore, the participants very much enjoyed their group exercise classes, felt connected to their classmates, and had very positive attitudes about their teacher and classmates.

\section{Relationships with the caring climate}

Simple correlation coefficients and simple linear regression lines were computed to address our primary research question. As shown in Table 1, the relationship between perceptions of a caring climate and indices of positive engagement were positive and, in general, of small to moderate strength [12]. The more participants perceived the psychological climate in their group exercise class to endorse caring the more enjoyment they indicated and the more connected they felt with their classmates. Furthermore, the more the participants perceived a caring climate the more likely they were to have positive attitudes about their instructor and their classmates.

Four simple linear regressions were computed using perceptions of the caring climate as the predictor variable and enjoyment, connectedness, attitude toward classmates, 
Table 1. Descriptive statistics and correlations of variables

\begin{tabular}{lccccc}
\hline Measure & 1 & 2 & 3 & 4 & 5 \\
\hline 1. Caring Climate & 0.96 & $0.51^{*}$ & $0.66^{*}$ & $0.34^{*}$ & $0.29^{*}$ \\
2. Enjoyment & & 0.91 & $0.50^{*}$ & $0.28^{*}$ & $0.23^{*}$ \\
3. Connectedness & & & 0.94 & $0.34^{*}$ & $0.53^{*}$ \\
4. Attitudes toward Instructor & & & & 0.73 & $0.43^{*}$ \\
5. Attitude toward Classmates & & & & & 0.81 \\
M & 4.72 & 4.60 & 6.21 & 4.70 & 4.67 \\
SD & 0.47 & 0.63 & 0.90 & 0.46 & 0.52 \\
\hline
\end{tabular}

Cronbach's alpha values are on the diagonal. ${ }^{*}-p<0.01$

attitude toward instructor as criterion variables. Results suggested that caring significantly predicted connectedness, $R^{2}=0.43, F(1,172)=130.23, p<0.001$, enjoyment, $R^{2}=0.26, F(1,172)=60.01, p<0.001$, attitudes toward instructor, $R^{2}=0.11, F(1,172)=21.98, p<0.001$, and attitudes toward classmates, $R^{2}=0.08, F(1,172)=15.34$, $p<0.001$. Analysis of the coefficients revealed that exercisers' perceptions of a caring climate significantly predicted their self-reported connectedness, $b=1.258, \beta=0.656$, $t(172)=11.412, p<0.000$, enjoyment, $b=0.682, \beta=0.509$, $t(172)=7.751$, attitudes instructor, $b=0.330, \beta=0.337$, $t(172)=4.688, p<0.001$, and attitudes toward classmates, $b=0.314, \beta=0.286, t(172)=3.917, p<0.001$.

\section{Discussion}

The intent of this study was to examine the relationship between college students' perceptions of being valued, supported, and respected in their physical activity classes, and key indicators of psychological engagement across three types of group physical activity courses and within males and females. Research examining the influence of motivational climate, and specifically the influence of the caring climate, on physical activity classes is emerging. This study supports the notion of building a caring climate in college physical activity settings. Findings offer clear support for the relevance and importance of a caring climate in fostering the experience of college students engaged in group physical activity courses.

\section{Mean differences}

In support of our hypothesis, perceptions of a caring climate did not differ by group physical activity course type or sex. Students enrolled in exercise, sport, and martial arts courses perceived similar amounts of caring. This is an important finding because it suggests that outcomes of a caring climate may be experienced in a wide variety of group physical activity courses and are not relegated to one type of group physical activity course. Previous research has examined college aerobic courses [8], as well as a variety of physical activity courses [9]. It also suggests that caring is more a function of the instructor than the type of course. Furthermore, males and females mean levels of a perceived caring climate did not differ, indicating that both sexes are equally able to perceive the verbal, non-verbal, and interpersonal behaviors associated with a caring climate. However, previous research on gender differences among motivation for physical activity is mixed. Some research suggests that males and females differ in their preferences of physical activity; males may prefer more competition based activities, while females may enjoy more collegial activities [16]. Other research suggests that females are more likely to continue to participate in physical activity for external reasons, such as weight loss and appearance [31].

\section{Caring in relation to optimal engagement}

Perceptions of a caring climate among college students enrolled in group exercise courses predicted feelings of connectedness. This is a novel relationship as yet unexplored in the physical activity literature. The more students felt safe, comfortable, welcomed every day and treated with kindness in their group physical actvity class, the more they felt supported, understood, listened to, and valued by others in their class. It is possible that feelings of connectedness encourage greater engagement in and adherence to physical activity regimens because of the sense of social cohesion engendered in such settings [32]. This finding may also have ramifications outside of the physical activity arena. The sense of connectedness that students experience in caring group exercise courses might serve as a buffer against the depression and other negative mental health outcomes often experienced by students with poor social support networks on college campuses [26].

College students' perceptions of a caring psychological climate were positively related to self-reported enjoyment. Thus, the more students felt valued, supported, and 
respected in their group physical activity class the more likely they were to indicate that they enjoyed the class, had fun during the class, and the more they felt as if the time flew while engaged in their physical activity. This finding supports our hypothesis and prior research with youth and adolescents involved in soccer [21] and research focused on the impact of a socially enriched leadership style on novice exercisers' levels of enjoyment [19, 30]. It is possible the interpersonal warmth inherent in a caring climate results in increased positive affect which may be experienced as enjoyment. It is also possible that participating in a caring physical activity setting allows participants to feel at ease with themselves and experience less social comparison, appearance-related social comparison, and self presentation concerns $[6,17]$, which may result in greater enjoyment. These findings are important because enjoyment and fun are valuable goals in their own right and are primary reasons why college students participate in physical activity [28].

Lastly, perceptions of a caring psychological climate were positively associated with attitudes toward classmates and instructor. In other words, the more participants felt valued, welcomed, and supported in their group activity class the more they liked and got along with their classmates and instructor. However, the relatively small variance accounted for in attitudes toward both instructor and classmates suggest there additional sources for forming these attitudes exist. It is likely that the students' competence, as well as their prior experiences with the activity, influence attitudes, among other things. These findings support previous work in youth and adolescent sport [21,39]. Our findings suggest that it might be useful to tap into group-based attitudes (i.e., attitudes about instructor and classmates), particularly given the increased popularity of group physical activity opportunities. It is possible that these attitudes contribute in important ways to engagement and, ultimately, the amount of physical activity engaged in.

This study has some limitations that should be considered. First, this research employed a cross sectional design at one university and, thus, inferences relative to cause and effect and generalizability cannot be made. Studies that replicate and extend the current work, as well as research that employs longitunal designs or examines the impact of climate interventions, would address this shortcoming. Second, we did not control for class size. It would be informative to examine if class size moderates the relationship between caring and psychological outcomes. Third, it is likely that the enjoyment of these college physical activity courses is partly a reflection of the comfort and enjoyment already experienced with the activity prior to taking the course. Students' desires to learn a new activity could also contribute to their social psychological experience in the class. Regardless, it is clear that enjoyment is vital to physical activity adherence. Lastly, we measured outcomes one would logically associate with greater physical activity, but did not assess actual physical activity. Determining if students actually move more in caring group physical activity courses would be useful information.

Despite these limitations, this research invites some considerations for professionals with vested interests in college students' well-being. Collaborating with and providing education to fitness instructors on the importance of creating a caring climate in fitness classes for college students is a relatively new area of study. Although most people are aware of the benefits of and need for more physical activity, psychosocial variables are often overlooked. Administrators and instructors of group fitness courses can play an important role in promoting physical activity by discussing strategies to promote a positive social psychological climate. Our findings suggest that creating a caring climate in university physical activity courses is advantageous to fostering multiple indicators of engagement. There are numerous strategies that can be shared with class instructors to create a caring climate [7]. For example, on the first day of class instructors can set the stage by saying, "I'm so happy to be here today and excited to get to know all of you. This will be a great class because we are going to get more fit, work together, and make new friends." The instructor can introduce themself and allow time for students to introduce themselves to each other. Such actions communicate what is valued and begins to create a caring climate. The instructor can take time each class period to acknowledge and welcome each student by greeting them by name as they enter, checking in to see how things are going, and patting them on shoulder. Additionally, the instructor can encourage members to be kind and supportive with each other by suggesting students share their goals with each other, pairing students together during the workout, and asking students to give other class members a high five during breaks. Lastly, instructors can end each class by wishing them a good rest of their day. These strategies are not complicated to implement, but care must be taken to intentionally create a supportive atmosphere in which everyone feels welcomed, valued, and respected.

Group physical activity courses are a popular and important avenue for engaging in exercise on college campuses. College students are not immune to the pressing health concerns that accompany increasing rates of overweight, obesity, and sedentary behavior [28]. As a result, understanding how to foster college students' level of engagement for physical activity is of paramount importance. We examined college students' perceptions of a caring climate in group exercise classes in relation to their feelings of group connectedness, enjoyment, and attitudes toward their classmates and their instructors. Our findings suggest that one viable strategy for improving the experience of students engaged in group physical activity classes is to encourage the creation of a caring climate. 
Conflict of interest: Authors state no conflict of interest.

\section{References}

1. Ames C., Archer J. (1998) Achievement goals in the classroom: Students' learning strategies and motivation processes. J. Educ. Psychol., 80: 260-267. DOI: 10.1037/0022-0663.80.3.260.

2. Ames C. (1992) Classrooms: Goals, structures, and student motivation. J. Educ. Psychol., 84: 261-271. DOI: 10.1037/0022-0663.84.3.261.

3. Armstrong S., Oomen-Early J. (2009) Social connectedness, self-esteem, and depression symptomatology among collegiate athletes versus nonathletes. J. ACH., 57: 521-526. DOI: 10.3200/JACH.57.5.521-526.

4. Bandura A. (1989) Human agency and social cognitive theory. Am. Psychol., 44: 1175-1184. DOI: 10.1037/0003066X.44.9.1175.

5. Bassuk S.S., Manson J.E. (2005) Epidemiological evidence for the role of physical activity in reducing risk of type 2 diabetes and cardiovascular disease. J. Appl. Physiol., 99: 1193-1204. DOI: 10.1152/ japplphysiol.00160.2005.

6. Brewer B.W., Diehl N.S., Cornelius A.E., Joshua M.D., Van Raalte J.L. (2004) Exercising caution: Social physique anxiety and protective self-presentational behaviour. J. Sci. Med. Sport, 7: 47-55. DOI:10.1016/S14402440(04)80043-4.

7. Brown T.C., Fry M.D. (2011) Helping members commit to exercise: Specific strategies to impact the climate at fitness centers. J. Sport Psychol. Action, 2: 70-80. DOI: 10.1080/21520704.2011.582803.

8. Brown T.C., Fry M.D. (2013) Association between females' perceptions of college aerobic class motivational climates and their responses. Women Health, 53: 843-857. DOI: 10.1080/03630242.2013.835298.

9. Brown T.C., Fry M.D. (2014) College exercise class climates, physical self-concept, and psychosocial well-being. J. Clin. Sport Psychol., 8: 299-313. DOI: 10.1123/ jcsp.2014-0031.

10. Buckworth J., Nigg C. (2004) Physical activity, exercise, and sedentary behavior in college students. $J$. $A C H$., 53: 28-34. DOI: 10.3200/JACH.53.1.28-34.

11. Calfas K.J., Sallis J.F., Lovato C.Y., Campbell J. (1994) Physical activity and its determinants before and after college graduation. Med. Exerc. Nutr. Health, 3: 323-334.

12. Cohen J. (1988) Statistical power analysis for the behavioral sciences. Hillsdale, NJ: Erlbaum.

13. Duda J.L., Nicholls J.G. (1992) Dimensions of achievement motivation in schoolwork and sport. J. Educ. Psychol., 84: 290-299. DOI: 10.1037/0022-0663.84.3.290.

14. Dumith S.C., Gigante D.P., Domingues M.R., Kohl III H.W. (2011) Physical activity change during adolescence: a systematice review and a pooled analysis. Int. J. Epidemiol., 40: 685-698. DOI: 10.1093/ije/dyq272.

15. Dzewaltowski D.A., Noble J.M., Shaw J.M. (1990) Physical activity participation: Social cognitive theory versus the theories of reasoned action and planned behavior. J. Sport Exerc. Psychol., 12: 388-405.

16. Egli T., Bland H.W., Melton B.R., Czech D.R. (2011) Influence of age, sex, and race on college students' exercise motivation of physical activity. J. ACH., 59: 399-409. DOI: $10.1080 / 07448481.2010 .513074$.

17. Fitzsimmons-Craft E.E., Harney M.B., Brownstone L.M., Higgens M.K., Bardone-Cone A.M. (2012) Examining social physique anxiety and disordered eating in college women: The roles of social comparison and body surveillance. Appetite, 59: 796-805. DOI: 10.1016/j. appet.2012.08.019.

18. Fox KR. The influence of physical activity on mental well-being. Public Health Nutr. 1999; 2:411-418. DOI:10.1017/S1368980099000567

19. Fox L.D., Rejeski W.J., Gauvin L. (2000) Effects of leadership style and group dynamics on enjoyment of physical activity. Am. J. Health Promot., 14: 277-283. DOI: 10.4278/0890-1171-14.5.277.

20. Fry M.D., Newton M. (2003) Application of achievement goal theory in an urban youth tennis setting. J. Appl. Sport Psychol., 15: 50-66. DOI: 10.1080/10413200305399.

21. Fry M.D., Gano-Overway L.A. (2010) Exploring the contribution of the caring climate to the youth sport experience. J. Appl. Sport Psychol., 22: 294-304. DOI: 10.1080/10413201003776352.

22. Fry M.D., Guivernau M., Kim M.-S., Newton M., GanoOverway L.A., Magyar M.T. (2012) Youth perceptions of a caring climate, emotional regulation, and psychological well-being. Sport Exerc. Perform. Psychol., 1: 44-57. DOI: $10.1037 / \mathrm{a} 0025454$.

23. Gano-Overway L.A. (2013) Exploring the connections between caring and social behaviors in physical education. Res. Q. Exerc. Sport, 84: 104-114. DOI: 10.1080/02701367.2013.762322.

24. Green K. (2002) Physical education and the 'couch potato society'-part 1. Eur. J. Phys. Educ., 7: 95-107. DOI: 10.1080/1740898020070203.

25. Haywood K.M. (1991) The role of physical education in the development of active lifestyles. Res. Q. Exerc. Sport, 67: 151-156. DOI: 10.1080/02701367.1991.10608705.

26. Hefner J., Eisenberg D. (2009) Social support and mental health among college students. Am. J. Orthopsychiatry, 79: 491-499. DOI:10.1037/a0016918.

27. Humpel N., Owen N., Leslie E. (2002) Environmental factors associated with adults' participation in physical activity: A review. Am. J. Prev. Med., 22: 188-199. DOI:10.1016/S0749-3797(01)00426-3.

28. Keating X.D., Guan J., Pinero J.C., Bridges D.M. (2005) A meta-analysis of college students' physical 
activity behaviors. J. ACH., 54: 116-126. DOI: 10.3200/ JACH.54.2.116-126.

29. Lowery S.E., Kurpius S.E.R., Befort C., Blanks E.H., Sollenberger S., Nicpon M.F., Huser L. (2005) Body image, self-esteem, and heatlh-related behaviors among male and female first year college students. J. Coll. Stud. Dev., 46: 612-623. DOI: 10.1353/csd.2005.0062.

30. Leslie E., Owen N., Salmon J., Bauman A., Sallis J., Lo S.K. (1999) Insufficiently active Australian college students: perceived personal, social, and environmental influences. Prev. Med., 28: 20-27. DOI:10.1006/ pmed.1998.0375.

31. Lauderdale M.E., Yli-Piipari S., Irwin C.C., Layne T.E. (2015) Gender differences regarding motivation for physical activity among college students: A self-determination approach. The Physical Educator, 72: 153-172.

32. McNeill L.H., Kreuter M.W., Subramanian S.V. (2006) Social environment and physical activity: a review of concepts and evidence. Soc. Sci. Med., 63: 1011-1022. DOI: 10.1016/j.socscimed.2006.03.012.

33. Nelson T.F., Gortmaker S.L., Subramanian S.V., Wechsler H. (2007) Vigorous physical activity among college students in the United States. J. Phys. Act. Health, 4: 495-508.

34. Newton M., Fry M., Watson D., Gano-Overway L.A., Kim M.-S., Magyar M.T., Guivernau M. (2007) Psychometric properties of the Caring Climate Scale in a physical activity setting. Revista de Psicologia del Deporte, 16: 67-84.

35. Noddings N. (1992) The Challenge to Care in Schools: An Alternative Approach to Education. New York, NY: Teachers College Press.

36. Owens L.M., Ennis C.D. (2005) The ethic of care in teaching: An overview of supportive literature. Quest., 57: 392-425. DOI: 10.1080/00336297.2005.10491864.

37. Petosa R.L., Suminski R., Hortz B. (2003) Predicting vigorous physical activity using social cognitive theory. Am. J. Health Behav., 27: 301-310. DOI: 10.5993/ AJHB.27.4.2.

38. Resnick M.D., Harris L.J., Blum R.W. (1993) The impact of caring and connectedness on adolescent health and well-being. J. Paediatr. Child. Health, 29: S3-S9. DOI: 10.1111/j.1440-1754.1993.tb02257.x.

39. Rhodes R.E., Courneya K.S. (2003) Investigating multiple components of attitude, subjective norm, and perceived control: An examination of the theory of planned behaviour in the exercise domain. Br. J. Soc. Psychol., 42: 129-146. DOI: 10.1348/014466603763276162.

40. Richer S.F., Vallerand R.J. (1995) Supervisors' interactional styles and subordinates' intrinsic and extrinsic motivation. J. Soc. Psychol., 135: 707-722. DOI: 10.1080/00224545.1995.9713974.

41. Seifriz J.J., Duda J.L., Chi L. (1992) The relationship of perceived motivational climate to intrinsic motivation and beliefs about success in basketball. J. Sport Exerc. Psychol., 14: 375-391.

42. Smith R.E., Smoll F.L., Curtis B. (1979) Coach effectiveness training: A cognitive-behavioral approach to enhancing relationship skills in youth sport coaches. J. Sport Psychol., 1: 59-75.

43. Standage M., Duda J.L., Ntoumanis N. (2003) Predicting motivational regulations in physical education: the interplay between dispositional goal orientations, motivational climate and perceived competence. J. Sports Sci., 21: 631-647. DOI: 10.1080/0264041031000101962.

44. Standage M., Duda J.L., Ntoumanis N. (2005) A test of self-determination theory in school physical education. Br. J. Educ. Psychol., 75: 411-433. DOI: 10.1348/000709904X22359.

45. Stice E., Hayward C., Cameron R.P., Killen J.D., Taylor C.B. (2000) Body-image and eating disturbances predict onset of depression among female adolescents: a longitudinal study. J. Abnorm. Psychol., 109: 438-444. DOI: 10.1037/0021-843X.109.3.438.

46. Taliaferro L.A., Rienzo B.A., Pigg R.M., Miller M.D. (2009) Associations between physical activity and reduced rates of hopelessness, depression, and suicidal behavior among college students. J. ACH., 57: 427-436. DOI: 10.3200/JACH.57.4.427-436.

47. Telama R., Yang X., Viikari J., Välimäki I., Wanne O., Raitakari O. (2005) Physical activity from childhood to adulthood: a 21-year tracking study. Am. J. Prev. Med., 28: 267-273. DOI: 10.1016/j.amepre.2004.12.003.

48. Thune I., Furberg A.S. (2001) Physical activity and cancer risk: dose-response and cancer, all sites and sitespecific. Med. Sci. Sports Exerc., 33: S530-S550. DOI: 10.1097/00005768-200106001-00025.

49. VanKim N.A., Nelson T.F. (2013) Vigorous physical activity, mental health, perceived stress, and socializing among college students. Am. J. Health Promot., 28: 7-15. DOI:10.4278/ajhp.111101-QUAN-395.

50. Wallace L.S., Buckworth J., Kirby T.E., Sherman W.M. (2000) Characteristics of exercise behavior among college students: Application of social cognitive theory to predicting stage of change. Prev. Med., 31: 494-505. DOI: 10.1006/pmed.2000.0736.

51. Walling M.D., Duda J.L., Chi L. (1993) The perceived motivational climate in sport questionnaire: Construct and predictive validity. J. Sport Exerc. Psychol., 15: 172-183.

\section{Received 11.03.2017 \\ Accepted 08.06.2017}

(C) University of Physical Education, Warsaw, Poland 